\title{
A Minor Role of Host Fruit on the Parasitic Performance of Aganaspis daci (Hymenoptera: Figitidae) on Medfly Larvae
}

\author{
Luis de Pedro ${ }^{1,2,3, *,+(\mathbb{D})}$, Ahlem Harbi ${ }^{1,4,+}+^{\mathbb{D}}$, José Tormos ${ }^{2}$, Beatriz Sabater-Muñoz ${ }^{1,5,6} \mathbb{D}^{\mathbb{D}}$ and Francisco Beitia ${ }^{1} \mathbb{D}$ \\ 1 Unidad Asociada de Entomología IVIA-CIB CSIC, Centro de Protección Vegetal y Biotecnología, \\ Instituto Valenciano de Investigaciones Agrarias (IVIA), Ctra. Moncada a Náquera km 4.5, \\ 46113 Moncada, Spain; harbi.ahlem@hotmail.fr (A.H.); b.sabater.munyoz@gmail.com (B.S.-M.); \\ beitia_fra@gva.es (F.B.) \\ 2 Unidad de Zoología, Facultad de Biología, Universidad de Salamanca, 37007 Salamanca, Spain; \\ tormos@usal.es \\ 3 Department of Crop Protection, Biological Control and Ecosystem Services, Instituto Murciano de \\ Investigación y Desarrollo Agrario y Alimentario, C/Mayor s/n, La Alberca, 30150 Murcia, Spain \\ 4 High Agronomic Institute of Chott-Mariem, University of Sousse, Chott-Mariem 4042, Tunisia \\ 5 Smurfit Institute of Genetics, Trinity College, University of Dublin, Dublin2 D02 VF25 Dublin, Ireland \\ 6 Integrative Systems Biology Group, Institute for Plant Molecular and Cell Biology (IBMCP) from the \\ Spanish National Research Council (CSIC), Polytechnic University of Valencia (UPV), 46022 Valencia, Spain \\ * Correspondence: luis.depedro@carm.es; Tel.: +34-968-362-788 \\ + Both authors should be considered first author.
}

check for updates

Citation: de Pedro, L.; Harbi, A.; Tormos, J.; Sabater-Muñoz, B.; Beitia, F. A Minor Role of Host Fruit on the Parasitic Performance of Aganaspis daci (Hymenoptera: Figitidae) on Medfly Larvae. Insects 2021, 12, 345. https://doi.org/10.3390/

insects12040345

Academic Editors: Lukasz L. Stelinski and Brian T. Forschler

Received: 9 February 2021

Accepted: 10 April 2021

Published: 13 April 2021

Publisher's Note: MDPI stays neutral with regard to jurisdictional claims in published maps and institutional affiliations.

Copyright: (c) 2021 by the authors. Licensee MDPI, Basel, Switzerland. This article is an open access article distributed under the terms and conditions of the Creative Commons Attribution (CC BY) license (https:// creativecommons.org/licenses/by/ $4.0 /)$.
Simple Summary: The medfly, Ceratitis capitata, is one of the main pests of citrus and other fruits worldwide. One of the most promising parasitoids for the control of this pest is Aganaspis daci, which has been recently discovered in the Mediterranean Basin. The development of fruit pests is strongly affected by the host fruit and this is also expected to affect the parasitic performance of their natural enemies. Therefore, in this study, we measured both the olfactory and parasitic response of female Aganaspis daci to different fruit species that can host medfly larvae. This parasitoid was more attracted to apples and uninfested fruit and showed very similar parasitic activity among the different tested fruits. However, the parasitic performance differed significantly depending on the environmental conditions under which the assays were conducted, showing good results in the laboratory and a much poorer performance in greenhouse trials. We conclude that $A$. daci may be a good candidate to control the medfly in a range of different crops, but only when climatic conditions allow normal activity of this species.

Abstract: Host fruit is known to strongly affect the performance of both fruit pests and their potential natural enemies. This is particularly important in the control of tephritid fruit flies, whose larvae develop inside the fruit and thus create a set of foraging problems for parasitoids. In the present study, we assessed the response of female Aganaspis daci (Weld) (Hymenoptera: Figitidae), one of the most promising parasitoids for tephritid biocontrol in the Mediterranean Basin, to different potential host fruit species. We measured the olfactory response to medfly-infested and uninfested fruits, and several biological parameters of $A$. daci when different infested fruits were offered under both laboratory and greenhouse conditions. Our results showed that this parasitoid was significantly more attracted to apples and uninfested fruit. Moreover, parasitic activity was similar among the tested fruits under both conditions, showing very high values in the laboratory and a much poorer performance when conditions were variable. This suggests that $A$. daci may be a good candidate to be included in mass releases against the medfly regardless of the affected crop, but only when climate conditions are not expected to hinder its normal activity.

Keywords: host fruit; Aganaspis daci; Ceratitis capitata; medfly; parasitic performance; olfactory testing; population reduction; host fruit preference; inundative releases; hotspot control 


\section{Introduction}

The Mediterranean fruit fly (medfly) Ceratitis capitata (Wiedemann) (Diptera: Tephritidae) is currently one of the main pests for citrus and other fruit worldwide. Ceratitis capitata is a multivoltine species, is able to feed and develop in more than 330 plant host species, and has adapted to a wide range of climates [1,2]. These reasons have led to the expansion of this species throughout most temperate regions, where it causes significant economic losses due to direct damage to fruit and reduces exports to medfly-free areas $[3,4]$. Control programs against $C$. capitata have therefore become essential. In this regard, and after many years relying in the use of pesticides [5], the most used control strategies today are environmentally friendly methods such as the sterile insect technique (SIT), mass trapping, chemosterilant traps, or biological control through the use of parasitoids [6-8].

One of the most promising parasitoids for medfly control is Aganaspis daci (Weld) (Hymenoptera: Figitidae). It is a solitary larval-pupal endoparasitoid of tephritids that was first recorded in Malaysia and Taiwan as a parasitoid of Bactrocera dorsalis (Hendel) [9]. Due to the efficiency shown on different hosts from the genus Bactrocera Macquart (formerly Dacus) in its native area, this species was introduced into different countries for the control of various tephritid pests in the past decades, showing a remarkable biocontrol potential [10-15]. These introductions included several releases, mainly in the seventies, which aimed to control natural medfly populations in areas such as mainland France and Reunion Island. However, in these cases, the results obtained were not conclusive [16,17]. The understanding on the relationship between $A$. daci and C. capitata changed dramatically in 2003 when, for the first time, this parasitoid was found emerging naturally from medfly pupae, in fig fruits in the Greek island of Chios [18]. Since then, A. daci has also been observed attacking medfly in Spain in fig and citrus fruits [19,20], in Syria in guava, grapefruit, loquat, and peach [21,22] and in Tunisia and Morocco also in citrus (F. Beitia, personal communication). These reports suggest that $A$. daci may have adapted to the Mediterranean climate. As such, the parasitoid has established stable populations, where it uses the medfly as a host, in some Mediterranean countries.

Despite its presence in the Mediterranean Basin, the effectiveness of $A$. daci in controlling medfly in this area is still under study. Field recoveries in Greece [18] and Spain $[19,20]$ showed high rates of parasitism, but further observations revealed that the fertility of this species on C. capitata was very low compared with other parasitoids in Mediterranean areas [23-27]. Later studies conducted in the Valencian Community (Spain) [28,29] concluded that the low fertility in the field was attributed to the deleterious effect of temperature extremes on A. daci adults and juveniles. Despite this, A. daci could still oviposit throughout the whole year, causing high mortality of juvenile medfly and successfully reduced their populations. The Mediterranean climate, therefore, does not seem to be optimal for the establishment of several consecutive generations of $A$. daci. However, this species could be considered a promising candidate to be used in inundative releases or in hotspot control against C. capitata in the Mediterranean Basin.

The biocontrol potential of a natural enemy may vary substantially depending on the plant species being exploited by its polyphagous host [30]. Hence, the knowledge of how a natural enemy responds to the host plant exploited by the target pest is essential when planning biocontrol programs. This is particularly interesting in the relationship between tephritid fruit flies and their parasitoids. Tephritid pests usually exploit an extraordinary range of host species and the larvae are strongly affected by the properties of the fruit in which they develop [31]. On the other hand, their parasitoids need to oviposit on preimaginal stages of the flies, which cannot be seen from outside the fruit. These parasitoids must efficiently use a variety of visual and, especially, tactile and fruitderived chemical cues to successfully locate their hosts [32]. The ability of parasitoids to locate infested fruits, detect host larvae inside, and to bore the fruit's skin to lay their eggs is therefore crucial in the performance as biocontrol agents. However, to date, the host locating ability of $A$. daci on medfly larvae and the effect of host fruits on the foraging processes remains understudied. 
Therefore, in the present study, we aimed to assess how the females of $A$. daci respond to the fruits of potential medfly host species from the Mediterranean Basin. We tested the attractiveness of different fruits via olfactory testing. Furthermore, we assessed the effect of these fruits on several biological parameters that are indicative of the parasitic potential and compared these parameters among fruit types to establish a host fruit preference for A. daci females. This is expected to be useful to put into perspective the relevance of host fruit in A. daci parasitic performance and, as a result, to be able to adequately plan hotspot control programs or inundative releases of $A$. daci against the medfly in the studied area.

\section{Materials and Methods}

\subsection{Study Centre, Insect Rearing, and Host Fruits}

All experiments in this study were performed in compliance with current Spanish law. Insects were obtained from laboratory colonies at the Instituto Valenciano de Investigaciones Agrarias (IVIA, Valencia, Spain). The A. daci colony was established in 2010 from individuals reared from field collected medfly larvae in figs from the nearby area of Bétera (Valencia, Spain). Since then, the laboratory rearing has been maintained, using C. capitata as a host. Specifically, medfly larvae mixed with an artificial diet mainly constituted by wheat bran, sugar, and brewer's yeast were offered to parasitoids to allow oviposition, as indicated in de Pedro [33] (rearing conditions $27 \pm 2{ }^{\circ} \mathrm{C}, 65 \% \pm 10 \% \mathrm{RH}, 16: 8$ (L:D) photoperiod). The medfly has been reared at the IVIA since 2008, using the method of Pérez-Hinarejos and Beitia [25] (rearing conditions: $27 \pm 2{ }^{\circ} \mathrm{C}, 65 \% \pm 10 \% \mathrm{RH}, 16: 8$ (L:D) photoperiod), in which medfly eggs were sown on the same type of the artificial diet mentioned above. The fruits used in the study were chosen based on several aspects such as their organoleptic properties, their availability in the market and their socioeconomic relevance in the Mediterranean area. Four types of fruits were selected: apple (Malus domestica Borkh, cv. Royal Gala), orange (Citrus sinensis (L.) Osbeck, var. Navel), peach (Prunus persica L., var. Nectarin), and clementine mandarins (Citrus clementina Ex. Hort. Tan., var. Clemenules). All these fruits were provided by local organic farmers. At IVIA, fruits were washed with chlorinated tap water and stocked in a cold-storage room at $8 \pm 1{ }^{\circ} \mathrm{C}$ and $50 \% \pm 5 \% \mathrm{RH}$ until their use for trials. Due to their availability throughout the year, apples were used as controls, i.e., the reference fruit for comparisons between treatments.

\subsection{Experimental Design}

Three experiments were carried out to assess the response of $A$. daci to the abovementioned fruit species.

\subsubsection{Olfactory Testing}

The response of $A$. daci to different olfactory stimuli was assessed by using a Y-tube olfactometer (Analytical Research Systems, ARS lt, Gainesville, FL, USA) in a series of trials performed under controlled conditions $\left(23 \pm 2{ }^{\circ} \mathrm{C}, 60 \% \pm 10 \% \mathrm{RH}, 2516\right.$ lux $)$. The glass Y-tube was $2.4 \mathrm{~cm}$ of diameter, with a $13.5 \mathrm{~cm}$ base and two arms, each $5.75 \mathrm{~cm}$ in length. This was connected to an air pump producing a unidirectional airflow of $150 \mathrm{~mL} / \mathrm{min}$ from the arms to the base (wind speed of $0.005 \mathrm{~m} / \mathrm{s}$ ). Airflow was established based on previous experiments with similar-sized insects [30,34-36]. The air pump was connected to two 5-L crystal jars containing the odor sources to be evaluated (in this case, test fruits). Each odor source was then connected to one of the arms of the Y-tube olfactometer. This methodology has been already described in previous works [36,37].

For all olfactory tests, 8-day-old $A$. daci females with previous parasitic experience on medfly larvae (i.e., obtained from the laboratory colony) were used. These specimens were individually isolated in 10-mL plastic tubes and left for $2-3 \mathrm{~h}$ in the olfactometer room to adapt to the assay conditions. In a first set of trials, our aim was to compare the response of $A$. daci females to infested vs. uninfested fruits, using apples, oranges, and peaches. Furthermore, we assessed whether time since infestation affected the female response, by comparing the attractiveness of uninfested apples vs. 1-day-old and 4- 
day-old infested apples. Finally, we also assessed the olfactory response to different types of fruits, all of which had the same infestation age. One-day-old infested apples, peaches, and oranges were pair-wise compared in these trials. Fruit infestation was artificially performed according to Martins et al. [38], digging 10 holes (5 $\mathrm{mm}$ diameter, $10-15 \mathrm{~mm}$ depth) in each fruit with a puncher and placing three medfly larvae (late L2early L3 stages) in each hole. Holes were subsequently closed with its corresponding fruit plug. Artificially infested fruits were stored at $25 \pm 2{ }^{\circ} \mathrm{C}$ in protected cages to avoid accidental infestation, for 1-4 days depending on the trial. Uninfested control fruits were subjected to the same drilling and storage process and thus reached the same ripeness stage, but no larvae were introduced.

Aganaspis daci females were tested individually in olfactory trials. Each female was placed at the base of the Y-tube using a small brush and allowed $15 \mathrm{~min}$ to respond [39]. A response was considered "positive" if the female walked at least $3 \mathrm{~cm}$ into one of the arms within this $15 \mathrm{~min}$ period, and was scored according to the chosen arm/odor source. All other responses were considered "negative", and the female was classified as a "nonresponder" and discarded from subsequent analyses. This procedure was repeated until at least 30 "positive" responses were recorded for each paired combination. To minimize any uncontrolled effect on the choice of the parasitoids, every 5 females/tests the Y-tube arms were flipped, and every 10 females/tests the Y-tube and the jars were thoroughly rinsed with soap, water, and acetone and then air-dried.

\subsubsection{Laboratory Assays}

The laboratory trials were performed in a climatic chamber under controlled conditions $\left(25 \pm 2{ }^{\circ} \mathrm{C} ; 70 \% \pm 10 \% \mathrm{RH} ; 16: 8\right.$ (L:D) photoperiod). Plastic boxes $(30 \mathrm{~cm} \times 25 \mathrm{~cm} \times 20 \mathrm{~cm})$, each with a muslin window for ventilation on the upper surface and containing water and sugar ad libitum, were used as parasitism units. Three 6-8-day-old $A$. daci mating couples were placed inside each parasitism unit. Artificially-infested fruits (as mentioned above according to [38] with 30 late L2-early L3 medfly larvae per fruit) were deposited inside parasitism units under two distinct treatments, establishing two different subassays as follows: "no-choice" tests in which three infested fruit of only one species were deposited in the parasitism units, or "host-choice" tests in which six infested fruits of two different species $(3+3)$ were introduced. In both tests, each infested piece of fruit was isolated in a $200-\mathrm{mL}$ plastic cup containing a layer of vermiculite to provide the larvae with a suitable substratum to pupate. The four abovementioned fruit species (apple, orange, peach, and clementine) were used in both tests, with apples always as the reference fruit in the host-choice tests. Three replicates of laboratory trials were performed, each consisting of fifteen experimental units: five of each fruit (no-choice) and five of fruit combination (hostchoice). Four additional parasitism units (two per treatment), containing no parasitoids, were used in each replicate to assess the natural mortality of the medfly larvae. The infested fruits were exposed to the parasitoids for 4 days; then, medfly pupae were recovered and put in ventilated Petri dishes (one per unit and fruit type) that were kept in a climatic chamber, as above, until the emergence of parasitoid and medfly adults. Emergences and closed puparia were counted. From these data, we analyzed the following variables to assess host preference by $A$. daci: effective fertility (as the number of descendants produced by the parasitoids), parasitoidism (=parasitoidism rate, as the number of descendants per recovered pupae), induced mortality (=mortality rate, as the number of pupae that remain closed per recovered pupae due to parasitoid activity), population reduction (as the sum of induced mortality plus parasitoidism), and offspring sex ratio (proportion of $A$. daci females among the total number of emerged parasitoids, $\left.n=q \% / \sigma^{7} \sigma^{7}+\phi q\right)$.

\subsubsection{Semi-Field Assays}

Semi-field trials were conducted to simulate natural conditions inside a greenhouse at IVIA, between March and July of 2014. The greenhouse was equipped with four plasticframed mesh cages $(125 \mathrm{~cm} \times 120 \mathrm{~cm} \times 70 \mathrm{~cm})$, each constituting a parasitism unit and 
containing water, sugar and honey as nutritional sources. Two translucent plastic topopen boxes $(40 \mathrm{~cm} \times 40 \mathrm{~cm} \times 40 \mathrm{~cm}$ ) were placed inside each of the cages, each box containing nine medfly-infested fruits deposited on a thin layer of vermiculite as described above. The fruit species differed between the two boxes in each cage, thus establishing a "host-choice" test. Three 6-8-day-old A. daci mating couples were released inside the four cages where the females could freely forage on the infested fruits for 4 days, and apples were again used as the reference fruit and compared with another fruit (orange, peach, or clementine) in each trial. After 4-days of exposure, all plastic boxes were closed and taken to the laboratory where the medfly pupae were recovered, put in ventilated Petri dishes (one per unit and fruit type) and kept under controlled conditions $\left(25 \pm 2{ }^{\circ} \mathrm{C}\right.$; $70 \% \pm 10 \% \mathrm{RH} ; 16: 8$ (L:D) photoperiod) until adults emerged. Emergences and closed puparia were counted, as indicated for the laboratory trials. Each pair-wise host-choice test was replicated three times. In each replicate, three infested fruits of each type were placed out of the cages, as control treatments to assess natural medfly larvae mortality. Effective fertility, parasitoidism, induced mortality, population reduction, and offspring sex ratio were analyzed as for laboratory trials.

\subsection{Data Analysis}

Data were analyzed using SPSS v22.0 (IBM SPSS, Chicago, IL, USA) with a significance set at $p=0.05$. Prior to the analysis, data normality was checked and data were transformed, where necessary.

Choice data of Aganaspis daci females derived from Y-tube olfactometer tests were analyzed with a Pearson's chi-squared $\left(\chi^{2}\right)$ test to compare the attractiveness between each pair of odor sources.

For laboratory and semi-field assays, Pearson's chi-squared $\left(\chi^{2}\right)$ test was also used to determine any significant differences in the offspring sex ratio depending on the type of fruit exposed. Linear mixed-model ANOVAs, with one fixed factor (fruit) and one random factor (replicate), were performed to test the effective fertility, parasitoidism, induced mortality and population reduction displayed by $A$. daci depending on the host fruit, in the no-choice laboratory tests. In the choice tests, the same analysis was performed but with the random factor ("replicates" in the laboratory assays, and "mesh cages" in the semi-field assays) hierarchical to fruits, since the two kinds of fruits were together in the same place. Induced mortality (i.e., corrected mortality) was calculated using the Schneider-Orelli formula [40] as follows:

Induced mortality $(\%)=[($ Treatment mortality $\%-$ Control mortality $\%) /(100-$ Control mortality $)] \times 100$

Here, population reduction is defined as the sum of induced mortality plus parasitoidism.

\section{Results}

\subsection{Olfactory Testing}

Olfactory tests revealed that $A$. daci females were more attracted to uninfested fruit than medfly-infested fruit (Figure 1). This preference was statistically significant when uninfested fruit was compared with 1-day-old infested peaches and oranges $\left(\chi^{2}=9.60, \mathrm{df}=1\right.$, $p=0.004)$, and with 4 -day-old infested apples $\left(\chi^{2}=6.67, \mathrm{df}=1, p=0.019\right)$. When comparing uninfested apples with 1-day-old infested apples, higher attraction to uninfested fruits was still observed, but it was not statistically significant $\left(\chi^{2}=4.25, \mathrm{df}=1, p=0.061\right)$. Pair-wise comparisons among different fruit types revealed $A$. daci females had a preference for apple odors, which was significant when compared with peach $\left(\chi^{2}=9.60, \mathrm{df}=1\right.$, $p=0.004)$ but not significant when compared with orange $\left(\chi^{2}=0.27, \mathrm{df}=1, p=0.797\right)$. Paradoxically, when comparing orange to peach, there was significant preference for peach odor $\left(\chi^{2}=6.67, \mathrm{df}=1, p=0.019\right)$. These results suggest that $A$. daci females, based on olfactory stimuli, seem to be more attracted by apple than by the two other fruits, and that peach is preferred to orange. 


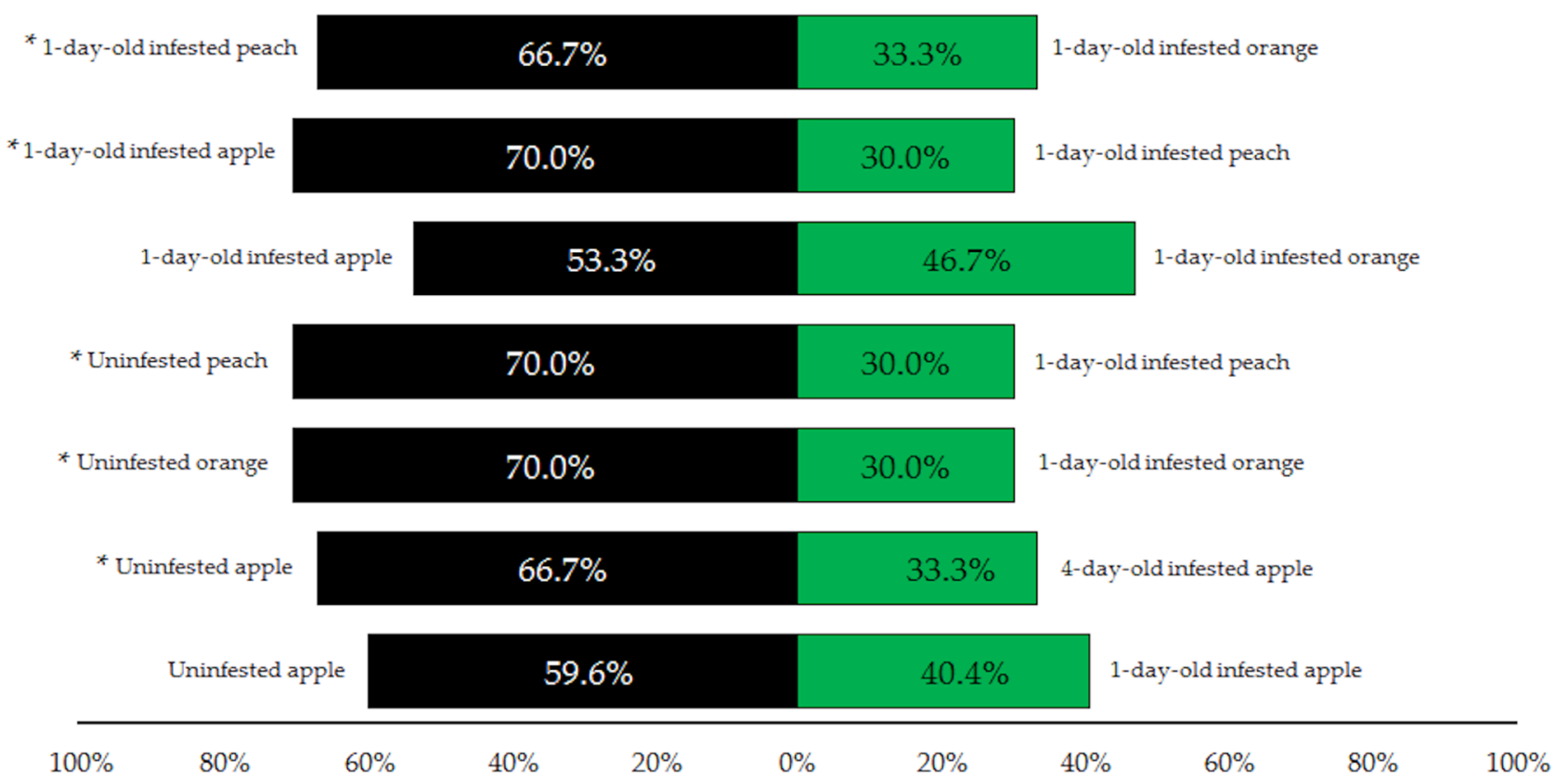

Figure 1. Percentages of $A$. daci females responding to each odor source (host fruit) in the different paired combinations of the olfactory tests. Asterisk $\left.{ }^{*}\right)$ indicates significant differences $(p \leq 0.05)$.

\subsection{Laboratory Assays}

Contrary to what was expected based on the olfactory responses, laboratory assays did not reveal a preference of $A$. daci females towards infested apples, oranges, clementines, or peaches, but it must be considered that the attraction towards volatiles (results in olfactometer) is completely different to the feasibility to parasitize (results in laboratory assays). In no-choice tests, ANOVA did not show significant differences among apples and any other fruits for parasitoidism, effective fertility, induced mortality, and population reduction (Tables 1 and 2), with a few exceptions. In this regard, effective fertility was significantly higher in A. daci parasitizing apple when compared with orange ( $p=0.043)$, and the population reduction caused by parasitoids on apple was also significantly higher than on peach $(p=0.006)$ (Tables 1 and 2). Meanwhile, chi-squared test revealed that the offspring sex ratio was significantly different between apple and clementine $\left(\chi^{2}=5.28\right.$, $\mathrm{df}=1, p=0.022)$, with a higher proportion of females in apple; and between apple and orange $\left(\chi^{2}=27.21, \mathrm{df}=1, p<0.001\right)$, with higher values in the latter (Table 2). However, no significant differences were observed between apple and peach $\left(\chi^{2}=0.09, \mathrm{df}=1, p=0.768\right)$. Additionally, for each fruit, this test also revealed a biased sex ratio in the offspring obtained from apple $\left(\chi^{2}=78.92, \mathrm{df}=1, p<0.001\right)$, clementine $\left(\chi^{2}=43.62, \mathrm{df}=1, p<0.001\right)$, peach $\left(\chi^{2}=28.50, \mathrm{df}=1, p<0.001\right)$, and orange $\left(\chi^{2}=3.52, \mathrm{df}=1, p=0.03\right)$. In all cases, the sex ratio was female-biased. 
Table 1. Linear mixed-model ANOVAs comparing parasitoidism, effective fertility, induced mortality and population reduction of $A$. daci between host fruit, in no-choice and host-choice tests, under laboratory conditions. $\mathrm{df}=\mathrm{degrees}$ of freedom; RV = residual variance; $\mathrm{BV}=$ block variance. Asterisks $\left(^{*}\right)$ indicate significant differences in each comparison.

\begin{tabular}{|c|c|c|c|c|c|c|c|}
\hline \multirow{2}{*}{\multicolumn{2}{|c|}{ Parameter }} & \multicolumn{3}{|c|}{ No-Choice Tests } & \multicolumn{3}{|c|}{ Host-Choice Tests } \\
\hline & & $\begin{array}{l}\text { Apple vs. } \\
\text { Clementine }\end{array}$ & $\begin{array}{l}\text { Apple vs. } \\
\text { Peach }\end{array}$ & $\begin{array}{l}\text { Apple vs. } \\
\text { Orange }\end{array}$ & $\begin{array}{l}\text { Apple vs. } \\
\text { Clementine }\end{array}$ & $\begin{array}{l}\text { Apple vs. } \\
\text { Peach }\end{array}$ & $\begin{array}{c}\text { Apple vs. } \\
\text { Orange }\end{array}$ \\
\hline \multirow{5}{*}{ Parasitoidism } & $\mathrm{F}$ & 1.12 & 2.90 & 8.14 & 0.26 & 8.57 & 0.06 \\
\hline & df & 1,24 & 1,24 & 1,24 & 1,24 & 1,24 & 1,24 \\
\hline & $p$ & 0.402 & 0.231 & 0.104 & 0.662 & 0.100 & 0.824 \\
\hline & $\sigma^{2}(\mathrm{RV})$ & 48.77 & 38.34 & 57.66 & 34.23 & 28.67 & 37.44 \\
\hline & $\sigma^{2}(\mathrm{BV})$ & $1 \times 10^{-8}$ & $1 \times 10^{-7}$ & $1 \times 10^{-9}$ & $1 \times 10^{-9}$ & $1 \times 10^{-9}$ & $1 \times 10^{-7}$ \\
\hline \multirow{5}{*}{$\begin{array}{l}\text { Effective } \\
\text { fertility }\end{array}$} & $\mathrm{F}$ & 0.01 & 0.10 & 21.63 & 3.50 & 17.26 & 16.17 \\
\hline & $\mathrm{df}$ & 1,24 & 1,24 & 1,24 & 1,24 & 1,24 & 1,24 \\
\hline & $p$ & 0.946 & 0.783 & $0.043^{*}$ & 0.202 & 0.053 & 0.057 \\
\hline & $\sigma^{2}(\mathrm{RV})$ & 43.55 & 48.59 & 32.68 & 40.33 & 27.57 & 31.12 \\
\hline & $\sigma^{2}(\mathrm{BV})$ & $1 \times 10^{-9}$ & $1 \times 10^{-8}$ & $1 \times 10^{-8}$ & $1 \times 10^{-8}$ & $1 \times 10^{-9}$ & $1 \times 10^{-9}$ \\
\hline \multirow{5}{*}{$\begin{array}{l}\text { Induced } \\
\text { mortality }\end{array}$} & $\mathrm{F}$ & 0.04 & 0.12 & 2.64 & 12.54 & 0.66 & 0.56 \\
\hline & $\mathrm{df}$ & 1,24 & 1,24 & 1,24 & 1,24 & 1,24 & 1,24 \\
\hline & $p$ & 0.852 & 0.765 & 0.245 & 0.071 & 0.502 & 0.531 \\
\hline & $\sigma^{2}(\mathrm{RV})$ & 39.23 & 44.54 & 52.34 & 28.11 & 31.55 & 36.68 \\
\hline & $\sigma^{2}(\mathrm{BV})$ & $1 \times 10^{-9}$ & $1 \times 10^{-8}$ & $1 \times 10^{-8}$ & $1 \times 10^{-8}$ & $1 \times 10^{-7}$ & $1 \times 10^{-8}$ \\
\hline \multirow{5}{*}{$\begin{array}{l}\text { Population } \\
\text { reduction }\end{array}$} & $\mathrm{F}$ & 2.48 & 177.16 & 3.62 & 0.11 & 0.23 & 0.02 \\
\hline & $\mathrm{df}$ & 1,24 & 1,24 & 1,24 & 1,24 & 1,24 & 1,24 \\
\hline & $p$ & 0.256 & 0.006 * & 0.198 & 0.770 & 0.678 & 0.896 \\
\hline & $\sigma^{2}(\mathrm{RV})$ & 37.12 & 42.68 & 50.12 & 41.12 & 46.89 & 38.22 \\
\hline & $\sigma^{2}(\mathrm{BV})$ & $1 \times 10^{-8}$ & $1 \times 10^{-8}$ & $1 \times 10^{-8}$ & $1 \times 10^{-9}$ & $1 \times 10^{-8}$ & $1 \times 10^{-9}$ \\
\hline
\end{tabular}

Table 2. Aganaspis daci mean parasitoidism, effective fertility, induced mortality, population reduction (mean $\pm \mathrm{SE}$ ) and offspring sex ratio $\left(n=q \uparrow / \sigma^{7} \sigma^{\lambda}+q \circ\right)$ comparing different fruit species in no-choice tests under laboratory conditions. Asterisks $\left(^{*}\right)$ indicate significant differences in each comparison.

\begin{tabular}{|c|c|c|c|c|c|c|}
\hline \multirow{2}{*}{ Parameter } & \multicolumn{2}{|c|}{ Apple vs. Clementine } & \multicolumn{2}{|c|}{ Apple vs. Peach } & \multicolumn{2}{|c|}{ Apple vs. Orange } \\
\hline & Apple & Clementine & Apple & Peach & Apple & Orange \\
\hline Parasitoidism (\%) & $59.5 \pm 4.6$ & $54.1 \pm 5.5$ & $49.4 \pm 5.7$ & $32.5 \pm 5.2$ & $59.6 \pm 4.1$ & $45.1 \pm 5.6$ \\
\hline Effective fertility & $43.1 \pm 3.6$ & $42.5 \pm 4.1$ & $37.1 \pm 4.7$ & $21.7 \pm 3.8$ & $48.3 \pm 4.7^{*}$ & $35.1 \pm 3.6^{*}$ \\
\hline Induced mortality (\%) & $34.5 \pm 4.8$ & $35.8 \pm 5.8$ & $49.6 \pm 6.3$ & $51.9 \pm 7.6$ & $19.8 \pm 2.8$ & $37.4 \pm 5.5$ \\
\hline Population reduction (\%) & $94.0 \pm 1.9$ & $89.8 \pm 3.1$ & $99.0 \pm 1.2 *$ & $84.4 \pm 2.5$ * & $79.4 \pm 4.0$ & $82.4 \pm 1.6$ \\
\hline Offspring sex ratio & 0.74 * & $0.68 *$ & 0.70 & 0.70 & $0.63 *$ & 0.66 * \\
\hline
\end{tabular}

In host-choice tests, ANOVA revealed no significant differences among apples and any of the other fruits for the measured variables (Tables 1 and 3). As in no-choice tests, both parasitoidism and effective fertility were numerically higher in apple than peach and orange (Table 3), but these differences were not statistically significant (Table 1). Similarly, population reduction was also higher in apple than in peach (Table 3), but statistical analysis did not support this difference (Table 1). Regarding the offspring sex ratio, chi-squared test revealed significant differences between apple and clementine $\left(\chi^{2}=13.45, \mathrm{df}=1, p<0.001\right)$ and apple and peach $\left(\chi^{2}=7.69, \mathrm{df}=1, p=0.006\right)$ (in both cases with a lower proportion of females emerged from apples) but not between apple and orange $\left(\chi^{2}=0.31\right.$, $\mathrm{df}=1$, $p=0.582$ ). In each fruit, offspring were significantly females biased (apple vs. clementine: $\chi^{2}=40.95, \mathrm{df}=1, p<0.001$; clementine: $\chi^{2}=109.48, \mathrm{df}=1, p<0.001$; apple vs. peach: $\chi^{2}=52.68, \mathrm{df}=1, p<0.001$; peach: $\chi^{2}=52.29, \mathrm{df}=1, p<0.001$; apple vs. orange: $\chi^{2}=16.70$, $\mathrm{df}=1, p<0.001$; orange: $\left.\chi^{2}=8.31, \mathrm{df}=1, p=0.005\right)$. 
Table 3. Aganaspis daci mean parasitoidism, effective fertility, induced mortality, population reduction (mean $\pm \mathrm{SE})$ and offspring sex ratio $\left(n=q \circ / \sigma^{\top} \sigma^{\top}+\phi o\right)$ comparing different fruit species in host-choice tests under laboratory conditions. Asterisks $(*)$ indicate significant differences in each comparison.

\begin{tabular}{ccccccc}
\hline \multirow{2}{*}{ Parameter } & \multicolumn{2}{c}{ Apple vs. Clementine } & \multicolumn{2}{c}{ Apple vs. Peach } & \multicolumn{2}{c}{ Apple vs. Orange } \\
\cline { 2 - 6 } & Apple & Clementine & Apple & Peach & Apple & Orange \\
\hline Parasitoidism (\%) & $48.5 \pm 6.6$ & $50.8 \pm 3.5$ & $51.3 \pm 4.1$ & $26.0 \pm 5.4$ & $60.3 \pm 5.8$ & $47.8 \pm 5.1$ \\
Effective fertility & $36.5 \pm 4.9$ & $41.9 \pm 2.9$ & $35.7 \pm 3.0$ & $16.7 \pm 3.9$ & $45.5 \pm 4.6$ & $31.3 \pm 3.3$ \\
Induced mortality (\%) & $27.4 \pm 5.6$ & $26.5 \pm 3.1$ & $46.0 \pm 5.0$ & $44.9 \pm 7.4$ & $16.2 \pm 2.5$ & $23.8 \pm 4.6$ \\
Population reduction (\%) & $75.9 \pm 7.4$ & $77.4 \pm 4.9$ & $97.4 \pm 2.1$ & $70.7 \pm 4.1$ & $76.6 \pm 5.8$ & $71.6 \pm 2.3$ \\
Offspring sex ratio & $0.69^{*}$ & $0.77^{*}$ & $0.71^{*}$ & $0.81^{*}$ & 0.61 & 0.59 \\
\hline
\end{tabular}

In summary, the abovementioned results indicate that $A$. daci parasitic activity in apple and clementine was very similar, showing high effective fertility values and rates of parasitoidism. Both parameters were numerically lower in orange and even more so in peach, but the higher induced mortality observed in these fruits led to similar overall values of population reduction. Considering apples as a reference and population reduction as the most complete indicator of parasitoid activity, the host fruit preference under laboratory conditions, which was very weak, could be established as similar between apple and clementine and, as in the olfactometer test, lower for orange and peach.

\subsection{Semi-Field Assays}

The results obtained under greenhouse conditions were similar to those observed in the laboratory. Semi-field assays did not show a clear preference of the parasitoid to apples, oranges, clementines, or peaches. ANOVA did not reveal significant differences among apples and the other fruits for parasitoidism, effective fertility, induced mortality, and population reduction (Tables 4 and 5). All these variables were very similar between apple and orange, while the comparisons "apple vs. clementine" and "apple vs. peach" showed higher (but not statistically significant) values of parasitoidism, population reduction, and, especially, effective fertility for apples (Table 5). Based on these results and especially on population reduction values, a very weak host fruit preference was observed for apple compared to the other tested fruits, similar than in the laboratory assays.

Pearson's chi-squared test only revealed significant differences between the offspring sex ratio of apples and peaches $\left(\chi^{2}=4.31, \mathrm{df}=1, p=0.043\right)$, but not in the comparisons "apple vs. clementine" $\left(\chi^{2}=1.84, \mathrm{df}=1, p=0.184\right)$ nor "apple vs. orange" $\left(\chi^{2}=0.53, \mathrm{df}=1\right.$, $p=0.499$ ). Additionally, in each fruit, a significantly female-biased offspring was revealed (apple vs. clementine: $\chi^{2}=56.70, \mathrm{df}=1, p<0.001$; clementine: $\chi^{2}=7.51, \mathrm{df}=1, p=0.010$; apple vs. peach: $\chi^{2}=72.71, \mathrm{df}=1, p<0.001$; peach: $\chi^{2}=35.49, \mathrm{df}=1, p<0.001$; apple vs. orange: $\chi^{2}=62.21, \mathrm{df}=1, p<0.001$; orange: $\chi^{2}=70.51, \mathrm{df}=1, p<0.001$ ).

Table 4. Linear mixed-model ANOVAs comparing parasitoidism, effective fertility, induced mortality, and population reduction of $A$. daci between combinations of host fruit under greenhouse conditions. $\mathrm{df}=$ degrees of freedom; $\mathrm{RV}=$ residual variance; $\mathrm{BV}=$ block variance.

\begin{tabular}{|c|c|c|c|c|}
\hline \multicolumn{2}{|c|}{ Parameter } & \multirow{2}{*}{$\begin{array}{c}\text { Apple vs. Clementine } \\
1.70\end{array}$} & \multirow{2}{*}{$\begin{array}{c}\text { Apple vs. Peach } \\
1.81\end{array}$} & \multirow{2}{*}{$\begin{array}{c}\text { Apple vs. Orange } \\
0.11\end{array}$} \\
\hline \multirow{5}{*}{ Parasitoidism } & $\mathrm{F}$ & & & \\
\hline & $\mathrm{df}$ & 1,18 & 1,18 & 1,18 \\
\hline & $p$ & 0.311 & 0.100 & 0.741 \\
\hline & $\sigma^{2}(\mathrm{RV})$ & 12.14 & 18.13 & 14.33 \\
\hline & $\sigma^{2}(\mathrm{BV})$ & $1 \times 10^{-8}$ & $1 \times 10^{-8}$ & $1 \times 10^{-8}$ \\
\hline
\end{tabular}


Table 4. Cont.

\begin{tabular}{|c|c|c|c|c|}
\hline \multicolumn{2}{|c|}{ Parameter } & \multirow{2}{*}{$\begin{array}{c}\text { Apple vs. Clementine } \\
0.13\end{array}$} & \multirow{2}{*}{$\begin{array}{c}\text { Apple vs. Peach } \\
0.22\end{array}$} & \multirow{2}{*}{$\begin{array}{c}\text { Apple vs. Orange } \\
0.03\end{array}$} \\
\hline \multirow{5}{*}{ Effective fertility } & $\mathrm{F}$ & & & \\
\hline & df & 1,18 & 1,18 & 1,18 \\
\hline & $p$ & 0.753 & 0.686 & 0.853 \\
\hline & $\sigma^{2}(\mathrm{RV})$ & 23.12 & 24.66 & 29.24 \\
\hline & $\sigma^{2}(\mathrm{BV})$ & $1 \times 10^{-8}$ & $1 \times 10^{-9}$ & $1 \times 10^{-8}$ \\
\hline \multirow{5}{*}{ Induced mortality } & $\mathrm{F}$ & 0.66 & 0.61 & 0.47 \\
\hline & df & 1,18 & 1,18 & 1,18 \\
\hline & $p$ & 0.502 & 0.516 & 0.565 \\
\hline & $\sigma^{2}(\mathrm{RV})$ & 15.22 & 23.33 & 19.22 \\
\hline & $\sigma^{2}(\mathrm{BV})$ & $1 \times 10^{-9}$ & $1 \times 10^{-8}$ & $1 \times 10^{-8}$ \\
\hline \multirow{5}{*}{ Population reduction } & $\mathrm{F}$ & 8.99 & 2.38 & 2.59 \\
\hline & df & 1,18 & 1,18 & 1,18 \\
\hline & $p$ & 0.096 & 0.263 & 0.249 \\
\hline & $\sigma^{2}(\mathrm{RV})$ & 18.22 & 28.44 & 24.12 \\
\hline & $\sigma^{2}(\mathrm{BV})$ & $1 \times 10^{-8}$ & $1 \times 10^{-8}$ & $1 \times 10^{-8}$ \\
\hline
\end{tabular}

Table 5. Aganaspis daci mean parasitoidism, effective fertility, induced mortality, population reduction (mean $\pm \mathrm{SE}$ ), and offspring sex ratio $\left(n=q+\sigma^{x} o^{x}+q o\right)$ comparing different fruit species in host-choice tests under greenhouse conditions. Asterisks $\left(^{*}\right)$ indicate significant differences in each comparison.

\begin{tabular}{ccccccc}
\hline \multirow{2}{*}{ Parameter } & \multicolumn{2}{c}{ Apple vs. Clementine } & \multicolumn{2}{c}{ Apple vs. Peach } & \multicolumn{2}{c}{ Apple vs. Orange } \\
\cline { 2 - 7 } & Apple & Clementine & Apple & Peach & Apple & Orange \\
\hline Parasitoidism (\%) & $11.5 \pm 4.6$ & $3.0 \pm 1.5$ & $16.2 \pm 6.1$ & $5.0 \pm 2.2$ & $14.5 \pm 3.9$ & $13.0 \pm 4.7$ \\
Effective fertility & $27.3 \pm 10.8$ & $6.7 \pm 3.5$ & $34.7 \pm 11.4$ & $9.2 \pm 4.2$ & $34.6 \pm 9.4$ & $32.6 \pm 9.3$ \\
Induced mortality (\%) & $19.3 \pm 3.3$ & $18.4 \pm 4.2$ & $18.2 \pm 4.2$ & $22.6 \pm 6.1$ & $9.8 \pm 2.7$ & $7.8 \pm 1.9$ \\
Population reduction (\%) & $30.7 \pm 7.2$ & $21.4 \pm 5.2$ & $34.4 \pm 7.3$ & $27.6 \pm 6.7$ & $24.3 \pm 4.4$ & $20.8 \pm 2.9$ \\
Offspring sex ratio & 0.79 & 0.82 & $0.78 *$ & $0.87^{*}$ & 0.77 & 0.79 \\
\hline
\end{tabular}

\section{Discussion}

The plant species that hosts an insect pest is known to be a key factor affecting the predatory or parasitic ability of its natural enemies [30,41,42]. This effect is particularly interesting in the case of the medfly Ceratitis capitata, one of the most economically damaging fruit pests in the Mediterranean Basin, due to the enormous range of potential hosts [1,2]. Therefore, in the present work, we evaluated the performance of the larval-pupal parasitoid Aganaspis daci, one of the most promising parasitoids of the medfly, on several fruit types that are economically relevant in the Mediterranean Basin and constitute potential hosts for medfly larvae. The first parameter considered in this study was the olfactory attractiveness of these fruits to the females of $A$. daci. Olfactory cues are essential for the orientation and parasitic behavior of parasitoids, since they are known to respond to allelochemicals released by plants and/or host insects as source of information for habitat location and host selection [43-46]. Interestingly, in the present study A. daci females were more attracted to uninfested fruit than to medfly-infested fruit and, moreover, in the case of apples, this innate preference for uninfested fruit was even more marked when compared to the 4-day-old infested fruits. This trend is completely opposite to that observed for other fruit fly parasitoids, such as the close species Aganaspis pelleranoi (Brèthes) [47] and the braconids Doryctobracon aureolatus (Szépligeti) [48] or Diachasmimorpha longicaudata (Ashmead). Aganaspis pelleranoi has been reported to be more attracted to volatiles of guavas infested with frugivorous larvae [47]. For its part, the females of D. longicaudata, which is one of the most widely employed species against tephritids [13], have also shown a significant preference for fruits infested with larvae of the medfly and/or other fruit flies [36,48]. In this regard, larvae in rotting fruits have long been believed to release or induce the formation of volatiles that are attractive to parasitoids when compared with uninfested ripe fruit [49-52]. For example, para-ethylacetophenone, an analog of a tephritid 
parasitoid attractant, has been identified as a major constituent of the volatiles produced by several species of tephritids including the medfly, and has been found to be attractive to $D$. longicaudata females [31]. According to our results, these volatiles seem to be innocuous or even repellent for $A$. daci, probably due to any of the differences observed among the sensillar equipment of this species and that of other medfly parasitoids including $D$. longicaudata and A. pelleranoi [53-56]. Thus, host location in A. daci seems to be initially driven by an attractive effect of the volatiles emitted exclusively by rotting fruits. Once the fruit surface is reached, we hypothesize that females may locate the host mainly by vibrotaxis using their mechanoreceptive sensillae, which are known to be specially advanced among those of fruit fly parasitoids [55]. Moreover, vibrotaxis has also been reported to allow close-range location in A. pelleranoi [47].

Olfactory pair-wised comparisons among fruit types revealed that this parasitoid seems to be more attracted to apples, followed by peaches and oranges. This could be explained by an attractive effect of some of the volatiles released by ripe apples, but also by a repellent effect of some compound emitted by the other fruits. In this regard, para-ethylacetophenone is known to be also a component of the volatiles produced by oranges [57], thus reinforcing the hypothesis that this compound may be repellent to A. daci females. Contrarily to our results, similar previous studies showed that $D$. longicaudata females were significantly more attracted to peach and citrus than apples, both using uninfested [30] and medfly-infested [36] fruits. All these trends highlight the specificity of volatile responses among fruit fly parasitoids and emphasize the need to perform further experiments to determine the specific compounds involved in olfactory preferences.

Laboratory and greenhouse trials confirmed that $A$. daci could parasitize tephritid larvae on different host fruits, supporting previous observations. This species had been previously observed parasitizing larvae from the genus Bactrocera Macquart on mango and cempedak in its area of origin [9], on guava in Egypt [15], and even on olive fruits in laboratory trials in Greece [58]. Moreover, $A$. daci has been reported emerging from larvae of C. capitata on figs [18,20], citrus [20], apples [59,60], loquats, guavas, grapefruits, and peaches [21,22].

These trials also revealed very similar parasitic performance of $A$. daci across the different host fruits, in spite of the observed olfactory preferences. In laboratory trials, choice tests did not reveal significant differences in any of the pair-wise comparisons, while no-choice tests only revealed significantly higher effective fertility in apples when compared with orange and greater population reduction ability on apple compared with peach. All these parameters tended to be higher in apple and clementine than in peach and orange, with the exception of induced mortality. This reveals a slight preference for the apple and clementine, which was in line with olfactory tests and suggests a certain association between preference and parasitoidism rate. This has been studied in other fruit fly parasitoids with conflicting results $[30,49,61]$. However, the experimental design of laboratory trials, in which little space is available for parasitoids and the access to the fruit surface is easy, leads to the belief that other factors beyond olfactory stimuli may better explain the observed results. Among these factors, several intrinsic characteristics of the fruits are known to have a decisive influence on the host-parasitoid interactions and, particularly, on host accessibility [62]. Fruit size and pulp depth, which are usually correlated, are often considered as the most important factors, since larvae sheltered deep within fruit pulp are more difficult to detect and less accessible to parasitoids [63]. Moreover, the development and movement of frugivorous larvae is influenced by fruit texture, mainly due to the physical features of the pulp and the consequent intrinsic forces [64-67]. The fruit skin firmness has a major influence on the ability of parasitoids to find the host and bore the peel to lay their eggs, this being easier in fruits of thin and soft skin, which offer low penetrating resistance $[62,63,68]$. Our results, in which mean population reduction was above $70 \%$ in all cases, suggest that the physical properties of all the fruits tested are suitable for high parasitic activity of $A$. daci on the medfly. This had already been proved for peaches [22] and apples [59,60], on which $A$. daci had already shown higher parasitoidism 
rates than $D$. longicaudata when released together [60]. This was contrary to expectations considering the longer ovipositor of this braconid [9,69,70], the hypothesis of Sivinski [71] that parasitoids with short ovipositor can only infest the larvae found in small fruits and the high firmness of the mesocarp in apples [65]. As in de Pedro et al. [60], we should conclude that the advanced sensillar equipment of $A$. daci [55] makes this parasitoid very efficient at searching for hosts inside fruit, most probably allowing a better detection of larvae even in fruits of significant size.

Greenhouse trials were designed to imitate conditions in the field. Unlike in laboratory trials, in semi-field assays olfactory and visual cues are expected to play an essential role in fruit/host searching and location by parasitoids [32], due to the greater space available and the large distance at which these cues are perceived [72]. Results showed, again, no significant differences among fruits in $A$. daci parasitic performance, even though we should highlight the numerally higher effective fertility and parasitoidism in apple and orange and the substantial induced mortality observed in peach. However, the values obtained in these trials for all fruits were surprisingly low compared with previous studies with the same experimental design $[59,60]$. This poor performance cannot be attributed to the host fruit species or to intrinsic factors of parasitoids, as previous studies have used apples and individuals of the same age and with the same parasitic experience as those used in this work. Considering the extreme sensitivity of $A$. daci to climatic conditions and especially to temperature $[28,29]$, together with the high temperatures recorded throughout the greenhouse trials (with an average over $27^{\circ} \mathrm{C}$ in most weeks of study), we hypothesized that this and some other environmental factors may have negatively affected its development and/or parasitic performance. In this regard, temperature, wind speed and direction, humidity, or light intensity are known to affect the olfactory response of parasitoids to fruits or host odors and, consequently, the host location process [43,73,74].

Temperature is also considered as the main factor affecting another of the measured parameters in our study, the sex ratio. A previous work [28] stated that, in the suitable developmental temperature range, the proportion of female offspring rises with increasing temperatures. In our study, offspring were female-biased in every trial and fruit species, and even more strongly under greenhouse conditions, where high temperatures were undoubtedly reached in the period of study. Female bias appears to be very common among hymenopteran parasitoids [75] and is always a desirable feature in biocontrol agents since females exert parasitic activity. However, this is not as relevant in inundative releases or hotspot control as it is in inoculative releases, where most control is provided by offspring of released organisms [76].

The host fruit preference suitability for $A$. daci females was established under the different conditions considered in this work. In laboratory and semi-field trials, this preference was established based on population reduction, which best summarizes the deleterious effect produced by parasitoids on pest populations. This innate preference was not strong in any case, in line with the observations of Ali [22] in some preliminary trials conducted in Western Syria and as one would expect for a parasitoid whose hosts are so polyphagous. In other medfly parasitoids, namely $D$. longicaudata, a strong hierarchical preference among apple, fig, orange, and peach has been reported by Segura et al. [30], but it should be addressed that, in this case, fruits were uninfested. Indeed, this and other species [77-79] are known to no longer respond according to innate preferences when hosts are present, seeking instead for those habitats in which the probability of host encounter is higher.

In our study, preference tended to be slightly biased towards apples, which are not amongst the most favorable hosts for C. capitata [66], unlike stone fruits and citrus, whose economic relevance in Spanish Mediterranean areas is much higher [80]. This could put the success of $A$. daci releases in this area into question. However, as mentioned before, the parasitic performance observed on stone fruits and citrus was not statistically lower, with very good results under controlled conditions and a weaker performance in a more varying environment. This information underlines climatic conditions, better than host 
fruit, as the key conditioning factor affecting the performance of $A$. daci as a biocontrol agent against the medfly in the Mediterranean Basin.

\section{Conclusions}

The present research constitutes, to our knowledge, the first exhaustive study on the effect of host fruit on the parasitic performance of $A$. daci against medfly, following preliminary results provided by Ali [22] in Western Syria. On the one hand, we conducted the first olfactometer trials reported for this parasitoid species, in which a clear preference for uninfested fruit over medfly-infested fruit was observed. One explanation to this fact may be a certain repellent effect caused by some volatile emitted by medfly larvae. Considering the observed preference for apples and peaches over oranges, and the presence of para-ethylacetophenone as a major constituent of the volatiles produced by both oranges and the medfly [31,57], this compound may be suggested as a possible repellent agent to $A$. daci females. On the other hand, we also confirmed, via laboratory and greenhouse trials, that $A$. daci is able to efficiently parasitize medfly larvae on different fruit species that are economically relevant in the Spanish Mediterranean area. This parasitic performance did not differ significantly among the host fruits, but between the different conditions under which trials were conducted. Under controlled conditions, the reduction of medfly populations caused by $A$. daci females was above $70 \%$ in every tested fruit, suggesting that physical properties of all these fruits are suitable for an adequate activity of this parasitoid. However, in greenhouse trials simulating natural conditions, the parasitic performance was very poor, which, considering similar previous studies [59,60], may be attributed to some environmental factor that could have negatively affected $A$. daci survival, development or parasitic ability. Thus, despite a certain host fruit preference being determined for each type of trial (with a slight dominance of apples in all cases), the effect of host fruit species on the parasitic performance of $A$. daci seems to be less relevant than, for example, that of environmental factors. In conclusion, our findings recommend the use of $A$. daci in biocontrol programs against the medfly in different crops, both in hotspot control or through inundative releases, but only at appropriate times of the year.

Author Contributions: Conceptualization, B.S.-M. and F.B.; methodology, B.S.-M. and F.B.; formal analysis, J.T. and F.B.; investigation, L.d.P., A.H., and F.B.; data curation, L.d.P., A.H., and F.B.; writing —original draft preparation, L.d.P.; writing—review and editing, J.T. and F.B.; supervision, J.T. and F.B.; project administration, F.B.; funding acquisition, F.B. All authors have read and agreed to the published version of the manuscript.

Funding: This research was funded by the Spanish Ministry of Science and Innovation (MICINN), grant number AGL2010-213-49-C02-02; the Spanish Ministry of Foreign affairs, the European Union and cooperation (AECID) grants A/01277/08 and A/024220/09; the Consellería de Agricultura, Pesca y Alimentación de la Generalitat Valenciana, with an institutional grant to the IVIA; and the Spanish and Tunisian Ministries of Education with the PhD fellowships to A.H. and L.d.P. (grant No. FPU-AP2010-2340).

Institutional Review Board Statement: Not applicable.

Data Availability Statement: The data presented in this study are available on request from the corresponding author.

Acknowledgments: We thank Fernando A. Ferrara, Azucena Gallardo-Paúls and Amparo Duato for their technical assistance. We also thank Alice Mockford from the University of Worcester, UK, for her comments on the written manuscript.

Conflicts of Interest: The authors declare no conflict of interest. The funders had no role in the design of the study; in the collection, analyses, or interpretation of data; in the writing of the manuscript, or in the decision to publish the results. 


\section{References}

1. Liquido, N.J.; Cunningham, R.T.; Nakagawa, S. Host plants of Mediterranean fruit fly (Diptera: Tephritidae) on the island of Hawaii (1949-1985 Survey). J. Econ. Entomol. 1990, 83, 1863-1878. [CrossRef]

2. Papadopoulos, N. Mediterranean fruit fly, Ceratitis capitata (Wiedemann) (Diptera: Tephritidae). In Encyclopedia of Entomology; Capinera, J.L., Ed.; Springer: Heidelberg, Germany, 2008; Volume 3, pp. 2318-2322.

3. Malacrida, A.R.; Gomulski, L.M.; Bonizzoni, M.; Bertin, S.; Gasperi, G.; Guglielmino, C.R. Globalization and fruitfly invasion and expansion: The medfly paradigm. Genetica 2007, 131, 1-9. [CrossRef]

4. Guillem-Amat, A.; Ureña, E.; López-Errasquín, E.; Navarro-Llopis, V.; Batterham, P.; Sánchez, L.; Perry, T.; Hernández-Crespo, P.; Ortego, F. Functional characterization and fitness cost of spinosad-resistant alleles in Ceratitis capitata. J. Pest. Sci. 2020, 93, 1043-1058. [CrossRef]

5. Martínez-Ferrer, M.T.; Campos, J.M.; Fibla, J.M. Field efficacy of Ceratitis capitata (Diptera: Tephritidae) mass trapping technique on clementine groves in Spain. J. Appl. Entomol. 2012, 136, 181-190. [CrossRef]

6. Delrio, G.; Cocco, A. Tephritidae. In Integrated Control of Citrus Pests in the Mediterranean Region; Vacante, V., Gerson, U., Eds.; Bentham Science: Sharja, United Arab Emirates, 2012; pp. 206-222.

7. Navarro-Llopis, V.; Primo, J.; Vacas, S. Efficacy of attract-and-kill devices for the control of Ceratitis capitata. Pest. Manag. Sci. 2012, 69, 478-482. [CrossRef] [PubMed]

8. Sciarretta, A.; Tabilio, M.R.; Lampazzi, E.; Ceccaroli, C.; Colacci, M.; Trematerra, P. Analysis of the Mediterranean fruit fly Ceratitis capitata (Wiedemann) spatiotemporal distribution in relation to sex and female mating status for precision IPM. PLoS ONE 2018, 13, e0195097. [CrossRef] [PubMed]

9. Weld, L.H. A New Species of Trybliographa (Hymenoptera: Cynipidae). Proc. Hawaii. Entomol. Soc. 1951, 14, $331-332$.

10. Clausen, C.P. Tephritidae (Trypetidae, Trupaneidae). In Introduced Parasites and Predators of Arthropod Pests and Weeds: A World Review; Clausen, C.P., Ed.; USDA-ARS: Washington, DC, USA, 1978; pp. 320-335.

11. Wharton, R.A.; Gilstrap, F.E.; Rhode, R.H.; Fischel-m, M.; Hart, W.G. Hymenopterous egg-pupal and larval-pupal parasitoids of Ceratitis capitata and Anastrepha spp. (Dip.: Tephritidae) in Costa Rica. Entomophaga 1981, 26, 285-290. [CrossRef]

12. Baranowski, R.; Glenn, H.; Sivinski, J. Biological control of the Caribbean fruit fly (Diptera: Tephritidae). Florida Entomol. 1993, 76, 245-251. [CrossRef]

13. Ovruski, S.M.; Aluja, M.; Sivinski, J.; Wharton, R.A. Hymenopteran parasitoids on fruit-infesting Tephritidae (Diptera) in Latin America and the southern United States: Diversity, distribution, taxonomic status and their use in fruit fly biological control. Integr. Pest. Manag. Rev. 2000, 4, 81-107. [CrossRef]

14. Andleeb, S.; Shahid, M.S.; Mehmood, R. Biology of parasitoid Aganaspis daci (Weld) (Hymenoptera: Eucoilidae). Pak. J. Sci. Ind. Res. 2010, 53, 201-204.

15. El-Heneidy, A.; Hosny, M.; Ramadan, M. Potential of the parasitoid species, Aganaspis daci (Weld) (Hymenoptera: Eucoilidae) against the peach fruit fly Bactrocera zonata (Saund.) (Diptera: Tephritidae). In Proceedings of the Ninth International Symposium on Fruit Flies of Economic Importance (ISFFEI), Bangkok, Thailand, 12-16 May 2014; pp. 395-400.

16. Mohamed, S.A.; Ramadan, M.M.; Ekesi, S. In and out of Africa: Parasitoids used for biological control of fruit flies. In Fruit Fly Research and Development in Africa-Towards a Sustainable Management Strategy to Improve Horticulture; Ekesi, S., Mohamed, S.A., de Meyer, M., Eds.; Springer International Publishing: Basle, Switzerland, 2016; pp. 325-368.

17. El-Heneidy, A.H.; Hosni, M.E.; Ramadan, M.M. Identity and biology of Aganaspis daci (Weld) (Hymenoptera: Figitidae), recently introduced to Egypt for biological control of Bactrocera zonata (Diptera: Tephritidae). Entomol. Mon. Mag. 2019, 155, 17-37. [CrossRef]

18. Papadopoulos, N.T.; Katsoyannos, B.I. Field parasitism of Ceratitis capitata larvae by Aganaspis daci in Chios, Greece. BioControl 2003, 48, 191-195. [CrossRef]

19. Verdú, M.J.; Falcó, J.V.; Beitia, F.; Sabater-Muñoz, B. Identificación de un nuevo agente de control biológico de Ceratitis capitata en España, el himenóptero eucoilino Aganaspis daci. In Proceedings of the XXVIII Jornadas de la Asociación Española de Entomología (AeE), Book of Abstracts, Ponferrada, Spain, 6-8 July 2011; p. 25.

20. Sabater-Muñoz, B.; Falcó, J.V.; de Pedro, L.; Tormos, J.; Asís, J.D.; Papadopoulos, N.; Verdú, M.J.; Beitia, F. First record, surveillance and biological parameters of Aganaspis daci (Hymenoptera: Figitidae), as parasitoid of Ceratitis capitata (Diptera: Tephritidae) in Spain. In Proceedings of the Second TEAM (Tephritid Workers of Europe Africa and the Middle East) Meeting; Biological Invasions of Tephritidae: Ecological and Economic Impacts, Kolymbari, Crete, Greece, 3-6 July 2012; p. 117.

21. Ali, A.Y.; Ahmad, A.M.; Amar, J.A. Hymenopteran parasitoids (Figitidae and Pteromalidae) of Ceratitis capitata (Diptera: Tephritidae) on loquat and guava in Tartous, Syria. Biocontrol Sci. Technol. 2015, 25, 223-228. [CrossRef]

22. Ali, A.Y.; Ahmad, A.; Ammar, J.; Darwish, R. Influence of host fruit species of medfly Ceratitis capitata on the parasitism level of Aganaspis daci. Arab J. Plant. Prot. 2016, 34, 95-97. [CrossRef]

23. Beitia, F.; Pérez-Hinarejos, M.; Garzón, E.; Santiago, S.; Tarazona, I.; Malagón, J.; Tormos, J.; Falcó, J.V. Lucha biológica contra Ceratitis capitata: Himenópteros parasitoides autóctonos. Terralia 2007, 63, 34-44.

24. Garzón-Luque, E.; Beitia, F.; Falcó, J.V. Parasitism of Diachasmimorpha tryoni (Hymenoptera: Braconidae) on the host Ceratitis capitata (Diptera: Tephritidae) under Mediterranean temperatures. IOBC/WPRS Bull. 2008, 38, 125-129.

25. Pérez-Hinarejos, M.; Beitia, F. Parasitism of Spalangia cameroni (Hymenoptera, Pteromalidae), an idiobiont parasitoid on pupae of Ceratitis capitata (Diptera, Tephritidae). IOBC-WPRS Bull. 2008, 38, 130-133. 
26. Rossi Stacconi, M.V.; Grassi, A.; Dalton, D.T.; Miller, B.; Ouantar, M.; Loni, A.; Ioriatti, C.; Walton, V.M.; Anfora, G. First field records of Pachycrepoideus vindemiae as a parasitoid of Drosophila suzukii in European and Oregon small fruit production areas. Entomologia 2013, 1, e3. [CrossRef]

27. Harbi, A.; de Pedro, L.; Ferrara, F.; Tormos, J.; Beitia, F.; Sabater-Muñoz, B. Parasitism activity of Diachasmimorpha longicaudata (Ashmead) (Hymenoptera: Braconidae) and Aganaspis daci (Weld) (Hymenoptera: Figitidae) against Ceratitis capitata (Wiedemann) (Diptera: Tephritidae) under Mediterranean climatic conditions. In Proceedings of the Ninth International Symposium on Fruit Flies of Economic Importance (ISFFEI), Bangkok, Thailand, 12-16 May 2014; pp. 401-410.

28. De Pedro, L.; Beitia, F.; Sabater-Muñoz, B.; Asís, J.D.; Tormos, J. Effect of temperature on the developmental time, survival of immatures and adult longevity of Aganaspis daci (Hymenoptera: Figitidae), a natural enemy of Ceratitis capitata (Diptera: Tephritidae). Crop. Prot. 2016, 85, 17-22. [CrossRef]

29. De Pedro, L.; Beitia, F.; Sabater-Muñoz, B.; Harbi, A.; Ferrara, F.; Polidori, C.; Asís, J.D.; Tormos, J. Parasitism of Aganaspis daci against Ceratitis capitata under Mediterranean climate conditions. Entomol. Exp. Appl. 2017, 163, 287-295. [CrossRef]

30. Segura, D.F.; Nussenbaum, A.L.; Viscarret, M.M.; Devescovi, F.; Bachmann, G.E.; Corley, J.C.; Ovruski, S.M.; Cladera, J.L. Innate host habitat preference in the parasitoid Diachasmimorpha longicaudata: Functional significance and modifications through learning. PLoS ONE 2016, 11, e0152222. [CrossRef]

31. Stuhl, C.; Sivinski, J.; Teal, P.; Paranhos, B.; Aluja, M. A compound produced by fruigivorous Tephritidae (Diptera) larvae promotes oviposition behavior by the biological control agent Diachasmimorpha longicaudata (Hymenoptera: Braconidae). Environ. Entomol. 2011, 40, 727-736. [CrossRef]

32. Godfray, H.C.J. Parasitoids: Behavioral and Evolutionary Ecology; Princeton University Press: Princeton, NJ, USA, 1994.

33. De Pedro, L. Bases para Implementar la Lucha Biológica Contra Ceratitis capitata (Diptera: Tephritidae) Mediante el Empleo de Aganaspis daci (Hymenoptera: Figitidae). Ph.D. Thesis, Universidad de Salamanca, Salamanca, Spain, 2017.

34. Wei, J.N.; Kang, L. Electrophysiological and behavioral responses of a parasitic wasp to plant volatiles induced by two leaf miner species. Chem. Senses 2006, 31, 467-477. [CrossRef] [PubMed]

35. Faraone, N.; Svensson, G.P.; Anderbrant, O. Attraction of the larval parasitoid Spintherus dubius (Hymenoptera: Pteromalidae) to feces volatiles from the adult apion weevil Host. J. Insect Behav. 2017, 30, 119-129. [CrossRef] [PubMed]

36. Harbi, A.; de Pedro, L.; Ferrara, F.A.A.; Tormos, J.; Chermiti, B.; Beitia, F.; Sabater-Muñoz, B. Diachasmimorpha longicaudata parasitism response to medfly host fruit and fruit infestation age. Insects 2019, 10, 211. [CrossRef] [PubMed]

37. Pérez-Hedo, M.; Urbaneja, A. Prospects for predatory mirid bugs as biocontrol agents of aphids in sweet peppers. J. Pest. Sci. 2015, 88, 65-73. [CrossRef]

38. Martins, D.S.; Skouri, W.; Chermiti, B.; Aboussaid, H.; Messoussi, S.E.; Ourfdou, K.; Carboneu, E.; Sabater-Muñoz, B.; Beitia, F. Analysis of two larval-pupal parasitoids (Hymenoptera, Braconidae) in the biological control of Ceratitis capitata (Wiedemann) in Spanish Mediterranean Areas. In Proceedings of the 8th International Symposium on Fruit Flies of Economic Importance (ISFFEI), Valencia, Spain, 26 September-1 October 2010; pp. 252-258.

39. McGregor, R.R.; Gillespie, D.R. Olfactory responses of the omnivorous generalist predator Dicyphus hesperus to plant and prey odours. Entomol. Exp. Appl. 2004, 112, 201-205. [CrossRef]

40. Püntener, W. Manual for Field Trials in Plant. Protection, 2nd ed.; Agricultural Division, Ciba Geigy: Basle, Switzerland, 1981.

41. Ode, P.J. Plant chemistry and natural enemy fitness: Effects on herbivore and natural enemy interactions. Annu. Rev. Entomol. 2006, 51, 163-185. [CrossRef]

42. Stoepler, T.M.; Lill, J.T.; Murphy, S.M. Cascading effects of host size and host plant species on parasitoid resource allocation. Ecol. Entomol. 2011, 36, 724-735. [CrossRef]

43. Vinson, S.B. Host selection by insect parasitoids. Annu. Rev. Entomol. 1976, 21, 109-133. [CrossRef]

44. Edwards, P.J.; Wratten, S.D. Ecologia das Interaçoes Entre Insetos e Plantas; EDUSP: Sao Paulo, Brazil, 1981.

45. Vet, L.E.M.; Dicke, M. Ecology of infochemical use by natural enemies in a tritrophic context. Annu. Rev. Entomol. 1992, 37, 141-172. [CrossRef]

46. De Siqueira, K.M.M.; de Farias, A.M.I. Resposta de fêmeas de Encarsia formosa Gahan (Hymenoptera: Aphelinidae) aos odores do hospedeiro e da planta-hospedeira em olfatômetro de quatro vias. Bragantia 2003, 62, 447-450. [CrossRef]

47. Guimaraes, J.A.; Zucchi, R.A. Parasitism behavior of three species of Eucoilinae (Hymenoptera: Cynipoidea: Figitidae) fruit fly parasitoids (Diptera) in Brazil. Neotrop. Entomol. 2004, 33, 217-224. [CrossRef]

48. Silva, J.W.P.; Bento, J.M.S.; Zucchi, R.A. Olfactory response of three parasitoid species (Hymenoptera: Braconidae) to volatilesof guavas infested or not with fruit fly larvae (Diptera: Tephritidae). Biol. Control. 2007, 41, 304-311. [CrossRef]

49. Leyva, J.L.; Browning, H.W.; Gilstrap, F.E. Effect of host fruit species, size, and color on parasitization of Anastrepha ludens (Diptera: Tephritidae) by Diachasmimorpha longicaudata (Hymenoptera: Braconidae). Environ. Entomol. 1991, 20, 1469-1474. [CrossRef]

50. Eben, A.; Benrey, B.; Sivinski, J.; Aluja, M. Host species and host plant effects on preference and performance of Diachasmimorpha longicaudata (Hymenoptera: Braconidae). Environ. Entomol. 2000, 29, 87-94. [CrossRef]

51. Jang, E.B.; Messing, R.H.; Klungness, L.M.; Carvalho, L.A. Flight tunnel responses of Diachasmimorpha longicaudata (Ashmead) (Hymenoptera: Braconidae) to olfactory and visual stimuli. J. Insect Behav. 2000, 13, 525-538. [CrossRef]

52. Eitam, A.; Holler, T.; Sivinski, J.; Aluja, M. Use of host fruit chemical cues for laboratory rearing of Doryctobracon areolatus (Hymenoptera: Braconidae), a parasitoid of Anastrepha spp. (Diptera: Tephritidae). Fla. Entomol. 2003, 86, 211-216. [CrossRef] 
53. Greany, P.D.; Hawke, S.D.; Carlysle, T.C.; Anthony, D.W. Sense organs in the ovipositor of Biosteres (Opius) longicaudatus, a parasite of the Caribbean fruit fly Anastrepha suspensa. Ann. Entomol. Soc. Am. 1977, 70, 319-321. [CrossRef]

54. Tormos, J.; Beitia, F.; Böckmann, E.A.; Asís, J.D.; Fernández, S. The preimaginal phases and development of Pachycrepoideus vindemmiae (Hymenoptera, Pteromalidae) on Mediterranean fruit fly, Ceratitis capitata (Diptera, Tephritidae). Microsc. Microanal. 2009, 15, 422-434. [CrossRef]

55. Tormos, J.; de Pedro, L.; Beitia, F.; Sabater-Muñoz, B.; Asís, J.D.; Polidori, C. Development, preimaginal phases and adult sensillar equipment in Aganaspis parasitoids (Hymenoptera: Figitidae) of fruit flies. Microsc. Microanal. 2013, 19, 1475-1489. [CrossRef]

56. Ovruski, S.M. Immature stages of Aganaspis pelleranoi (Brèthes) (Hymenoptera: Cynipoidea: Eucoilidae), a parasitoid of Ceratitis capitata (Wied.) and Anastrepha spp. (Diptera: Tephritidae). J. Hymenopt. Res. 1994, 3, 239.

57. Hernández, M.M.; Sanz, I.; Adelantado, M.; Ballach, S.; Primo, E. Electroantennogram activity from antennae of Ceratitis capitata (Wied.) to fresh orange airborne volatiles. J. Chem. Ecol. 1996, 22, 1607-1619. [CrossRef] [PubMed]

58. Moraiti, C.A.; Kyritsis, G.A.; Papadopoulos, N.T. Effect of the olive fruit size on the parasitism rates of Bactrocera oleae (Diptera: Tephritidae) by the figitid wasp Aganaspis daci (Hymenoptera: Figitidae), and first field releases of adult parasitoids in olive grove. Hell. Plant. Prot. J. 2020, 13, 66-77.

59. De Pedro, L.; Beitia, F.; Ferrara, F.; Sabater-Muñoz, B.; Asís, J.D.; Tormos, J. Effect of host density and location on the percentage parasitism, fertility and induced mortality of Aganaspis daci (Hymenoptera: Figitidae), a parasitoid of Ceratitis capitata (Diptera: Tephritidae). Crop. Prot. 2017, 92, 160-167. [CrossRef]

60. De Pedro, L.; Tormos, J.; Harbi, A.; Ferrara, F.; Sabater-Muñoz, B.; Asís, J.D.; Beitia, F. Combined use of the larvo-pupal parasitoids Diachasmimorpha longicaudata and Aganaspis daci for biological control of the medfly. Ann. Appl. Biol. 2019, 174, 40-50. [CrossRef]

61. Ovruski, S.; Van Nieuwenhove, G.; Bezdjian, L.; Albornoz-Medina, P.; Schliserman, P. Evaluation of Diachasmimorpha longicaudata (Hymenoptera: Braconidae) as a mortality factor of Ceratitis capitata (Diptera: Tephritidae) infesting Citrus species under laboratory and field-cage conditions. Biocontrol Sci. Technol. 2012, 22, 187-202. [CrossRef]

62. Sivinski, J. The influence of host fruit morphology on parasitization rates in the Caribbean fruit fly, Anastrepha suspensa. Entomophaga 1991, 36, 447-454. [CrossRef]

63. Sivinski, J.; Aluja, M. The roles of parasitoid foraging for hosts, food and mates in the augmentative control of tephritidae. Insects 2012, 3, 668-691. [CrossRef]

64. Calkins, C.O.; Webb, J.C. Temporal and seasonal differences in movement of the Caribbean fruit fly larvae in grapefruit and the relationship to detection by acoustics. Fla. Entomol. 1988, 71, 409-416. [CrossRef]

65. Zucoloto, F.S. Acceptability of different Brazilian fruits to Ceratitis capitata (Diptera: Tephritidae) and fly performance on each species. Braz. J. Med. Biol. Res. 1993, 26, 291-298.

66. Papadopoulos, N.T.; Katsoyannos, B.I.; Carey, J.R. Demographic parameters of the Mediterranean fruit fly (Diptera: Tephritidae) reared in apples. Ann. Entomol. Soc. Am. 2002, 95, 564-569. [CrossRef]

67. Tonina, L.; Giomi, F.; Sancassani, M.; Ajelli, M.; Mori, N.; Giongo, L. Texture features explain the susceptibility of grapevine cultivars to Drosophila suzukii (Diptera: Drosophilidae) infestation in ripening and drying grapes. Sci. Rep. 2020, 10, 10245. [CrossRef] [PubMed]

68. Jesus-Barros, C.R.; Adaime, R.; Oliveira, M.N.; Silva, W.R.; Costa-Neto, S.V.; Souza-Filho, M.F. Anastrepha (Diptera: Tephritidae) species, their hosts and parasitoids (Hymenoptera: Braconidae) in five municipalities of the state of Amapá, Brazil. Fla. Entomol. 2012, 95, 694-705. [CrossRef]

69. Sivinski, J.; Vulinec, K.; Aluja, M. Ovipositor length in a guild of parasitoids (Hymenoptera: Braconidae) attacking Anastrepha spp. fruit flies (Diptera: Tephritidae) in southern Mexico. Ann. Entomol. Soc. Am. 2001, 94, 886-895. [CrossRef]

70. Carmichael, A.E.; Wharton, R.A.; Clarke, A.R. Opiine parasitoids (Hymenoptera: Braconidae) of tropical fruit flies (Diptera: Tephritidae) of the Australian and South Pacific region. Bull. Entomol. Res. 2005, 95, 545-569. [CrossRef] [PubMed]

71. Sivinski, J.; Aluja, M.; Lopez, M. Spatial and temporal distribution of parasitoids of Mexican Anastrepha species (Diptera: Tephritidae) within the canopies of fruit trees. Ann. Entomol. Soc. Am. 1997, 90, 604-618. [CrossRef]

72. Vinson, B. How parasitoids locate their hosts: A case of insect espionage. In Insect Communication; Academic Press: London, UK, 1984; pp. 325-348.

73. Jones, R.L. Orientation by insects parasitoids. In Mechanisms in Insect Olfaction; Payne, T.L., Birch, M.C., Kennedy, C.E.J., Eds.; Clarendon Press: Oxford, UK, 1986; pp. 149-155.

74. Turlings, T.C.J.; Wackers, F.L.; Vet, L.E.M.; Lewis, W.J.; Tumlinson, J.H. Learning of host-finding cues by Hymenopterous parasitoids. In Insect Learning: Ecological and Evolutionary Perspectives; Papaj, D.R., Lewis, A.C., Eds.; Chapman and Hall: New York, NY, USA, 1993; pp. 51-78.

75. He, L.F.; Feng, D.D.; Li, P.; Zhou, Z.S.; Xu, Z.F. Reproductive modes and daily fecundity of Aenasius bambawalei (Hymenoptera: Encyrtidae), a parasitoid of Phenacoccus solenopsis (Hemiptera: Pseudococcidae). Fla. Entomol. 2015, 98, 358-360. [CrossRef]

76. Van Driesche, R.G.; Bellows, T.S. Augmentation of parasitoids, predators, and beneficial herbivores. In Biological Control; Springer: Boston, MA, USA, 1996; pp. 178-200.

77. Geervliet, J.B.F.; Vreugdenhil, A.I.; Dicke, M.; Vet, L.E.M. Learning to discriminate between infochemicals from different plant-host complexes by the parasitoids Cotesia glomerata and C. rubecula. Entomol. Exp. Appl. 1998, 86, 241-252. [CrossRef]

78. Tentelier, C.; Wajnberg, E.; Fauvergue, X. Parasitoids use herbivore-induced information to adapt patch exploitation behaviour. Ecol. Entomol. 2005, 30, 739-744. [CrossRef] 
79. Tentelier, C.; Fauvergue, X. Herbivore-induced plant volatiles as cues for habitat assessment by a foraging parasitoid. J. Anim. Ecol. 2007, 76, 1-8. [CrossRef] [PubMed]

80. Ministerio de Agricultura, Pesca y Alimentación (MAPA). Anuario de Estadística. Available online: https://www.mapa.gob.es/ es/estadistica/temas/default.aspx (accessed on 20 June 2020). 